\title{
Effects of omega-3 on androgenic activity in cadmium-induced
}

\section{hypertensive rats}

Dler Qader Gallaly ${ }^{1 *}$

\begin{abstract}
Background and objective: Cadmium is a widely distributed metal in the environment that causes testicular toxicity and various tissue damage associated with hypertension. Omega-3, an essential fatty acid, has been demonstrated to be an effective antioxidant and anti-inflammatory agent. This study aimed to investigate the toxic effects of cadmium on cardiovascular and reproductive systems in male rats and examine the possible protective effects of omega-3 against cadmium-induced hypertension and testicular dysfunctions.
\end{abstract}

Methods: The rats were divided into three groups. The first group served as the control, the second group received cadmium chloride in drinking water, and the third group received cadmium chloride plus omega- 3 for 28 days. Blood pressure and heart rate were estimated. Blood samples were collected; sexual hormones and other biochemical parameters were evaluated. Testes and epididymis were taken for semen analysis and histopathology.

Results: Significant adverse effects were seen in the studied parameters of the cardiovascular and reproductive systems after cadmium exposure, including hypertension, alteration in sperm parameters, weights of sex glands, and histological structures. In contrast, co-administration of omega-3 significantly reduced mean blood pressure, but improved sperm parameters and the histology of testis. No protective effect of omega-3 could be seen on male hormone and lipid profile parameters except high-density lipoprotein.

Conclusion: Exposure to cadmium induced hypertension, impaired testicular functions, and histology. Omega-3 has protective effects on vascular and testicular functions. Therefore, supplementation with omega-3 had a protective effect against cardiovascular and reproductive toxicity induced by cadmium.

Keywords: Cadmium; Omega-3; Blood pressure; Sperm parameter; Male hormones.

\section{Introduction}

Cadmium (Cd) is a toxic element and a common pollutant associated with many industrial processes. ${ }^{1}$ It is widely distributed in the environment and has high toxicity and mobility in the ecosystem. Exposure to $\mathrm{Cd}$ occurs mainly through the ingestion of contaminated food, water, inhalation, and tobacco smoking. Cd has a long biological half-life ( $>20$ years) and accumulates in the body, mostly in the liver, kidney, and intestines. Also, $\mathrm{Cd}$ accumulates in the testes for about $1-2 \%$ of an acute dose depending on age, body nutritional status, dosage, and the time exposure to $\mathrm{Cd}^{2}$ Cadmium affects the cardiovascular system negatively, and it is involved in producing several acute and chronic diseases such as hypertension, atherosclerosis, and endothelial dysfunction. $^{3}$ The most common mechanisms causing hypertension associated with $\mathrm{Cd}$ may include the interference with the renin-angiotensin system, impaired nitric oxide, oxidative stress, altered vascular response to the

${ }^{1}$ Department of Physiology, College of Medicine, Hawler Medical University, Erbil, I raq.

* Correspondence: dler.qader@hmu.edu.krd 
neurotransmitter, and disturbed $\mathrm{Ca}^{2+}$ signaling in the vascular muscle. A combination of two or more than a singular mechanism is needed to produce hypertension. ${ }^{4}$ Furthermore, endothelial cells have been shown to be sensitive to the toxic effects of $\mathrm{Cd}$, which leads to the impaired function of endothelial -and smooth muscle cells. This dysfunction of endothelial cells promotes the formation of atherosclerosis plague. ${ }^{5}$ In addition, many studies on humans, as well as different species of mammalians such as mice, rabbits, and rats, have established that exposure to $\mathrm{Cd}$ induces systemic toxicity, including testicular toxicity. ${ }^{6,7}$ The testes are extremely sensitive to Cd toxicity because of the blood-testis-barrier, which is a major target of $\mathrm{Cd}$ induced toxicity in the testis. The changes in the testis are related to the disruption of the blood-testis-barrier. ${ }^{8}$ A study done by Djuric and her team workers in 2015 showed that subacute intraperitoneal administration of cadmium chloride $\left(\mathrm{CdCl}_{2}\right)(1 \mathrm{mg} / \mathrm{kg} /$ day $)$ reduced the level of testicular testosterone and their mass and additionally resulted in microscopic and macroscopic changes as a consequence of developed oxidative stressby $\mathrm{Cd} .{ }^{9}$ The $\mathrm{Cd}$ also has a damaging effect on sperm parameters such as sperm morphology, sperm count in testes and epididymis ${ }^{10}$ and sperm motility. ${ }^{11}$ Nevertheless, several studies have been done to investigate the protective effect of several types of antioxidants in diminishing the toxic effects of $\mathrm{Cd}$. Of these can act as antioxidants; caffeine, ginger, vitamin $\mathrm{E}$, vitamin $\mathrm{C}$, and omega-3.12,13 Omega-3 is an essential fatty acid found in a large amount in fish oil containing eicosapentaenoic and docosahexaenoic acids. The supplementation of omega- 3 has many beneficial effects in patients with hyperlipidemia and diabetes. ${ }^{14}$ Several recent studies documented antioxidant, anti -inflammatory, and anti-apoptotic effects of omega-3 oil. Therefore, it is suggested to be a hopeful potential protective agent against different toxic stimuli. ${ }^{15}$
Omega-3 has also shown to have a protective effect against the $\mathrm{Cd}$ induced hepatotoxicity ${ }^{13}$ and might also have a beneficial effect in patients suffering from chronic inflammatory diseases like multiple sclerosis by increasing antiinflammatory lipid mediators. ${ }^{16}$ Additionally, a recent study done by Uygur et al. (2014) demonstrated that omega-3 pretreatment was favorable for spermatogenesis by reducing germ cell apoptosis and oxidative stress in an acute doxorubicin-induced testicular damage. ${ }^{17}$ Limited information, however, present about the protective effect of omega-3 on androgenic activity in $\mathrm{Cd}$-induced hypertensive rats. Therefore, this study aimed to investigate the possible harmful effects of $\mathrm{Cd}$ on the male reproductive system and sex hormone levels and study the protective effects of omega-3 on the cardiovascular system and androgenic activities in male albino rats.

\section{Methods}

\section{Animals}

Eighteen healthy male rats weighing $200-250 \mathrm{~g}$ of equivalent age groups were used in this study. They were housed in plastic cages bedded with wooden chips in the animal house of College of Medicine, Hawler Medical University. The animals were kept under room temperature $25^{\circ} \mathrm{C}$ with 12 hours' light and dark cycle. This study was approved by the Research Ethics Committee at the College of Medicine, Hawler Medical University.

\section{Experimental design}

Eighteen rats were divided randomly into three groups, six in each. The first group rats served as control and were given standard chow and tap water. The second group received rat chow and $\mathrm{CdCl}_{2}$ $(100 \mathrm{mg} / \mathrm{L})$ in drinking water ${ }^{18}$ for 28 days while the third group received $(100 \mathrm{mg} / \mathrm{L})$ $\mathrm{CdCl}_{2}$ in drinking water plus omega-3 oil $(4 \mathrm{gm} / \mathrm{kg} \mathrm{diet})^{13}$ for 28 days. Arterial blood pressure and heart rate were estimated for control and experimental rats using CODA monitor. At the end of the study, the rats 
were anesthetized with a combination of ketamine $(75 \mathrm{mg} / \mathrm{kg})$ and xylazine $(10 \mathrm{mg} /$ $\mathrm{kg}),{ }^{19}$ and blood samples were collected from each rat for hormones and other biochemical parameters. Testicles and epididymis were removed from the sacrificed rats to record the weight of testes and epididymis, and seminal fluid parameters were evaluated. Additionally, histological examination of the testicular tissue was performed for both control and treated groups for the evaluation of tissue abnormalities.

\section{Measurement of blood pressure}

Blood pressure was measured noninvasively in male albino rats by using the CODA system (Kent Scientific, Torrington, CT, USA). Rats were placed in warmed plastic cage used for tail-cuff, and blood pressure (BP) measurement and a warm water-bag monitored at a temperature between $35-37{ }^{\circ} \mathrm{C}$ was placed on top and round the rats for a stable temperature during the measurement of BP. Tails of rats were fixed with Occlusion Cuff (O-Cuff) and Volume Pressure Recording (VPR) Cuff according to the manufacturer's protocol, and readings were recorded for 10 cycles, and the average was used for estimation of BP.

\section{Sperm parameters}

The left epididymis was removed, and the caudal part was placed in a petri dish containing 5 milliliters $(\mathrm{ml})$ of normal saline and split with a surgical blade to open the duct to release its contents.

\section{Sperm viability}

To investigate the sperm viability, a drop of sperm suspension was placed on a clean glass slide and mixed with a drop of eosin-nigrosin stain solution. ${ }^{20} \mathrm{~A}$ thin smear was prepared and air-dried. The stained slides were then examined under the microscope with X100 magnification. Live (viable) sperm cells appeared white or light pink (unstained) while the dead (nonviable) sperm cells absorbed the stain and appeared dark pink. At least 200 sperms were counted, and the percentage of each was calculated.

\section{Sperm count}

The petri dish containing cauda homogenate was kept in the refrigerator for 24 hours to allow spermatozoa release from the walls. The petri dish was then spun to achieve a uniform sperm suspension, and one $\mathrm{ml}$ from the suspension was added to $7 \mathrm{ml}$ of normal saline in a small glass beaker. The sperm counting was then carried out with the Neubauer chamber cell counting of the haemocytometer, ${ }^{21}$ and total sperm concentration was calculated. Data are referred as sperm count in million $/ \mathrm{ml}$.

\section{Histological evaluation of testis}

Testes of control and treated rats were removed, weighed, and fixed in $10 \%$ buffered formalin ${ }^{22}$ for histological processing. The tissue processing was done by dehydration through ascending concentrations of ethanol $(70 \%, 80 \%, 95 \%$, $95 \%, 100 \%$, and $100 \%$ ) for 2 hours each, cleared in xylene, impregnation in paraffin wax. Sections were cut by microtome at $3 \mu \mathrm{m}$ thickness and placed on slides, fixed and dewaxed in the oven for 3 hours. Afterward, the slides were stained with haematoxylin for 10 minutes and eosin (1\%) for 2 minutes. ${ }^{23}$ The slides were examined under the light microscope for histological evaluation. Photomicrographs of the slides at 40X magnification were taken.

\section{Statistical analysis}

Data were analyzed statistically using Graph pad prism software version 7.03. All the data were summarized as mean \pm SE or as median (interquartile range) for continuous variables. Comparisons between groups had been made using the paired t-test, one-way analysis of variance (ANOVA), Tukey's multiple comparisons test, and a $P$ value of 0.05 or less was considered statistically significant. 


\section{Results}

Effects of cadmium alone and cadmium plus omega-3 on blood pressure and lipid profile

Rats exposed to cadmium as $\mathrm{CdCl}_{2}$ $(100 \mathrm{mg} / \mathrm{L})$ in drinking water for 28 consecutive days resulted in the induction of hypertension, as shown in Table 1. The mean blood pressure (MBP) was significantly $(P=0.01)$ increased in rats exposed to $\mathrm{Cd}(106.9 \pm 3.037)$ as compared to the control group $(91.63 \pm 1.88)$. Supplementation with omega-3 in a dose of $4 \mathrm{gm} / \mathrm{kg}$ diet significantly decreased MBP (92.47 \pm 3.678$)$ when compared with

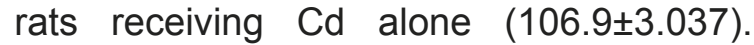
No significant differences $(P>0.05)$ in heart rate $(H R)$ were found among all three groups (Table 1). Administration of $\mathrm{Cd}$ alone resulted in a significant increase $\left(\begin{array}{ll}P & \leq 0.005\end{array}\right)$ in serum TG level $(87.06 \pm 9.174)$ when they were compared with control rats $(41 \pm 6.96)$. While, compared to the controls, administration of $\mathrm{Cd}$ plus omega-3 showed a significant increase in serum cholesterol (58.53 \pm 0.765$)$, serum TG $(81 \pm 8.534)$, and high density lipoprotein (HDL) $(41.22 \pm 1.413)$ as shown in Table 1. Additionally, compared to the rats exposed to $\mathrm{Cd}$ alone, rats fed with $\mathrm{Cd}$ plus omega-3 exhibited a significant increase in serum cholesterol and HDL. Contrariwise, the administration of $\mathrm{Cd}$ plus omega- 3 caused a significant reduction $(P=0.049)$ in serum low-density lipoprotein (LDL) level in comparing with normal rats (Table 1).

Table 1: Effects of cadmium and cadmium plus omega-3 on mean blood pressure, heart rate and lipid profile in normal and Cd-induced hypertensive rats.

\begin{tabular}{|c|c|c|c|c|c|c|}
\hline & Control & Cadmium & Cd+Omega-3 & & $P$ value & \\
\hline $\mathrm{MBP}(\mathrm{mmHg})$ & $91.63 \pm 1.88$ & $106.9 \pm 3.037$ & $92.47 \pm 3.678$ & 0.006 & 0.977 & 0.009 \\
\hline $\mathrm{HR}(\mathrm{b} / \mathrm{m})$ & $385.8 \pm 16.05$ & $363.6 \pm 9.84$ & $373.6 \pm 15.67$ & 0.523 & 0.817 & 0.872 \\
\hline Cholesterol (mg/dl) & $42.67 \pm 3.303$ & $47.28 \pm 2.156$ & $58.53 \pm 0.765$ & 0.362 & 0.001 & 0.009 \\
\hline TG (mg/dl) & $41.00 \pm 6.96$ & $87.06 \pm 9.174$ & $81.00 \pm 8.534$ & 0.005 & 0.013 & 0.864 \\
\hline HDL-C (mg/dl) & $30.2 \pm 0.734$ & $28.07 \pm 2.36$ & $41.22 \pm 1.413$ & 0.673 & 0.002 & 0.001 \\
\hline LDL-C (mg/dl) & $8.25 \pm 1.109$ & $5.00 \pm 1.732$ & $3.50 \pm 0.288$ & 0.189 & 0.049 & 0.662 \\
\hline
\end{tabular}

ab: a compared to b; ac: a compared to c; bc: b compared to c 
Effects of cadmium alone and cadmium plus omega-3 on sperm parameters

As shown in Table 2, the administration of $\mathrm{Cd} 100 \mathrm{mg} / \mathrm{L}$ in drinking water for 28 repeated days resulted in a significant reduction in both sperm count and viability (from $18.44 \mathrm{million} / \mathrm{ml}$ to $11.33 \mathrm{million} / \mathrm{ml}$ ) and (from $88.9 \%$ to $55.83 \%$ ) respectively. Supplement of omega-3 had shown a beneficial effect on sperm parameters when both sperm count (19.17 million/ml) and sperm viability (83.17) were improved as compared to rats received $\mathrm{Cd}$ alone (11.33 million/ml) and (55.83\%) respectively. However, no significant changes were recorded by comparison of the omega-3 treated group and the control (Table 2).

Effects of cadmium alone and cadmium plus omega-3 on male sexual hormones The treatment of rats with $\mathrm{Cd}(100 \mathrm{mg} / \mathrm{L})$ and omega-3 (4 $\mathrm{gm} / \mathrm{kg})$ along the experimental period, significantly increased the level of follicle stimulating hormone (FSH) compared to the control $(P=0.03)$. In addition, there were significant differences in estradiol levels among all groups, as shown in Table 3. Conversely, no significant changes were found in the hormonal levels of luteinizing hormone (LH), free- and total testosterone between the groups (Table 3).

Table 2: Effects of cadmium and cadmium plus omega-3 on sperm parameters in normal and Cd-induced hypertensive rats.

\begin{tabular}{lcccccc}
\hline Parameters & $\begin{array}{c}\text { Control } \\
(\mathbf{n}=6) \\
(\mathbf{a})\end{array}$ & $\begin{array}{c}\text { Cadmium } \\
(\mathbf{n}=6) \\
(\mathbf{b})\end{array}$ & $\begin{array}{c}\text { Cd+ Omega-3 } \\
(\mathbf{n}=6) \\
(\mathbf{c})\end{array}$ & \multicolumn{3}{c}{$\boldsymbol{P}$ value } \\
\hline Sperm counting $\left(10^{6} / \mathrm{ml}\right)$ & $18.44 \pm 1.059$ & $11.33 \pm 1.137$ & $19.17 \pm 1.475$ & 0.004 & 0.916 & 0.001 \\
& & & & & & \\
Sperm viability $(\%)$ & $88.9 \pm 1.373$ & $55.83 \pm 3.637$ & $83.17 \pm 2.651$ & 0.001 & 0.370 & 0.001 \\
\hline
\end{tabular}

Table 3: Effects of cadmium and cadmium plus omega-3 on hormonal levelsin normal and Cd-induced hypertensive rats.

\begin{tabular}{|c|c|c|c|c|c|c|}
\hline \multirow{2}{*}{ Parameters } & \multirow{2}{*}{$\begin{array}{c}\text { Control } \\
(n=6) \\
(a)\end{array}$} & \multirow{2}{*}{$\begin{array}{l}\text { Cadmium } \\
(n=6) \\
(b)\end{array}$} & \multirow{2}{*}{$\begin{array}{c}\text { Cd+Omega-3 } \\
(n=6) \\
\text { (c) }\end{array}$} & \multicolumn{3}{|c|}{$P$ value } \\
\hline & & & & ab & ac & bc \\
\hline Serum FSH (mlU/ml) & $1.723 \pm 0.058$ & $2.837 \pm 0.439$ & $3.083 \pm 0.382$ & 0.082 & 0.031 & 0.865 \\
\hline Serum LH (mlU/ml) & $3.132 \pm 0.156$ & $3.545 \pm 0.384$ & $3.638 \pm 0.281$ & 0.582 & 0.450 & 0.971 \\
\hline Testicular Testost. (ng/ml) & $1.548 \pm 0.591$ & $1.140 \pm 0.393$ & $0.960 \pm 0.43$ & 0.853 & 0.669 & 0.969 \\
\hline Free serum Testost. (pg/ml) & 3.89 & 4.48 & 1.08 & 0.415 & 0.908 & 0.229 \\
\hline Median (IQR) & $(2.60-8.33)$ & $(2.39-32.94)$ & $(0.76-5.37)$ & & & \\
\hline Estradiol (pg/ml) & $24.36 \pm 1.096$ & $21.03 \pm 0.437$ & $18.04 \pm 0.477$ & 0.015 & 0.001 & 0.029 \\
\hline
\end{tabular}


Effects of cadmium alone and cadmium plus omega-3 on testis- and epididymis weights

The results showed that $\mathrm{Cd}$ exposure in male rats has a significant impact on the weight of testis $(1.10 \mathrm{gm})$ and caudal epididymis $(0.21 \mathrm{gm}$.$) when compared$ with the controls $(1.33 \mathrm{gm})$ and $(0.29 \mathrm{gm})$ respectively. Nonetheless, rats exposed to $\mathrm{Cd}$ with omega-3 could significantly $(P=0.006)$ reduce the weight of testis (1.12 gm.) as compared to the control rats $(1.33 \mathrm{gm})$, as shown in Table 4 and Figure 1.

Table 4: Effects of cadmium and cadmium plus omega-3 on testis- and epididymis weights in normal and Cd-induced hypertensive rats.

\begin{tabular}{|c|c|c|c|c|c|c|}
\hline \multirow{2}{*}{ Parameters } & \multirow{2}{*}{$\begin{array}{c}\text { Control } \\
(n=6) \\
(a)\end{array}$} & \multirow{2}{*}{$\begin{array}{l}\text { Cadmium } \\
(n=6) \\
\text { (b) }\end{array}$} & \multirow{2}{*}{$\begin{array}{c}\text { Cd+Omega-3 } \\
(n=6) \\
\text { (c) }\end{array}$} & \multicolumn{3}{|c|}{$P$ value } \\
\hline & & & & $a b$ & ac & bc \\
\hline Weight of testis (gm) & $1.33 \pm 0.06$ & $1.10 \pm 0.02$ & $1.12 \pm 0.01$ & 0.003 & 0.006 & 0.916 \\
\hline Weight of caudal epididymis (gm) & $0.29 \pm 0.03$ & $0.21 \pm 0.01$ & $0.25 \pm 0.01$ & 0.028 & 0.279 & 0.413 \\
\hline
\end{tabular}
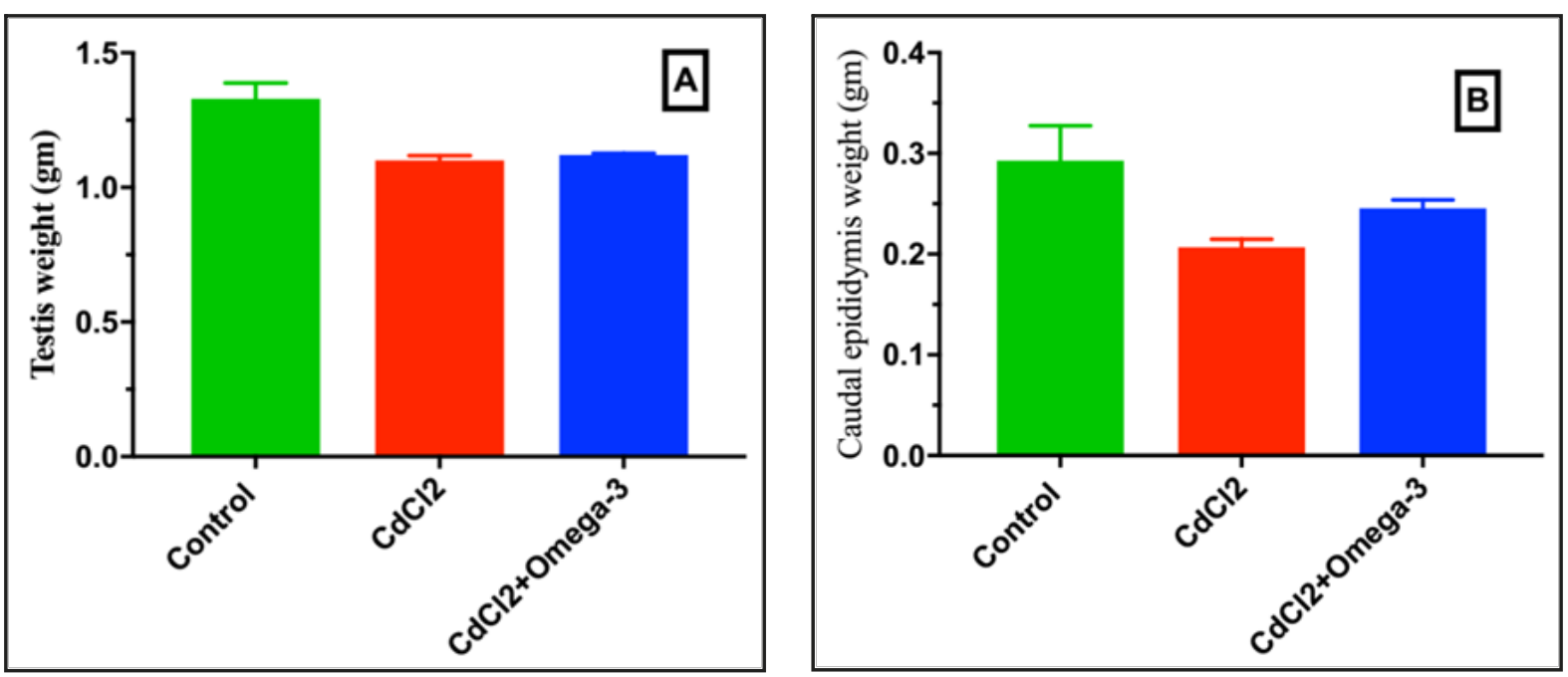

Figure 1: The effects of cadmium alone and cadmium plus omega- 3 on the weights of the testis $(A)$ and caudal epididymis $(B)$ in normal and Cd-induced hypertensive rats. 
Effects of cadmium alone and cadmium plus omega-3 on the histology of testes

The histopathological examination of control testes showed normal morphology (Figure 2, A). The testicular biopsy of rats exposed to $\mathrm{Cd}(100 \mathrm{mg} / \mathrm{L})$ in drinking water for a period of 28 days (Figure 2, B) showed a moderate to severe arrest in spermatogenesis with absence of spermatozoa in most of the tubular lumen as compared with the control rats in which the transverse sections of testis showed normal histological structure with complete spermatogenesis and presence of spermatozoa in most of the tubular lumen (Figure 2, A). However, the spermatogenesis in rats received both $\mathrm{Cd}$ plus omega- 3 was mildly arrested with the absence of spermatozoa in a few of the tubular lumen (Figure 2, C). In addition, severe congestion of inter-tubular blood vessels could be seen in rats treated with only Cd compared with the control group. Furthermore, Sertoli cells proliferation in some seminiferous tubules were seen in both studied groups as compared to the control group.

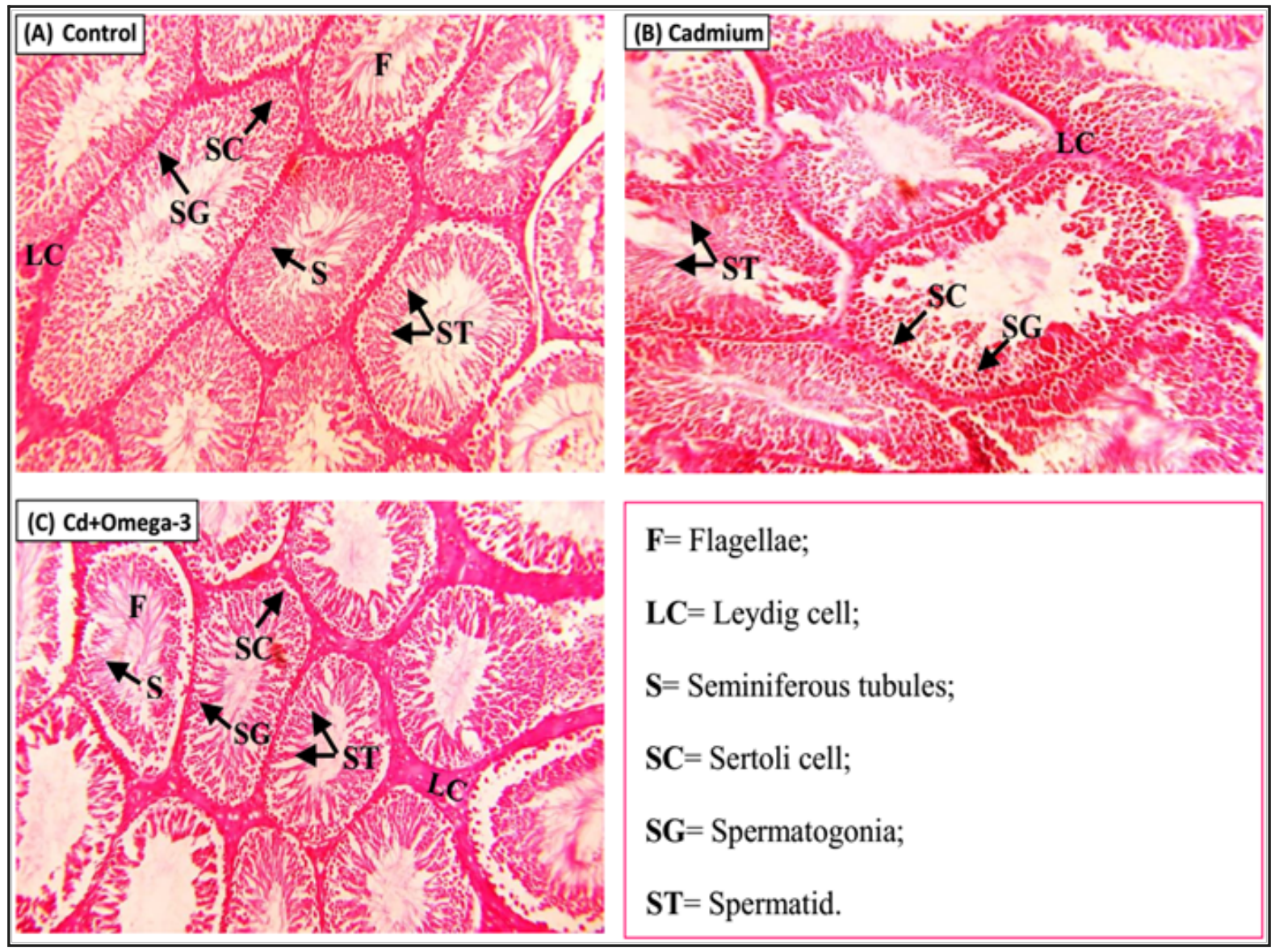

Figure 2: Histology of testis; (A) Control group, (B) Cadmium (Cd), and (C) Cadmium plus omega-3 treated groups. H\&E stain X40. 


\section{Discussion}

The results of this study confirmed the induction of hypertension by $\mathrm{Cd}$, which is a non-essential element with no specific roles in human physiology. Cadmium in high concentration disrupts the normal biological functions in the body. ${ }^{4}$ Rats received $100 \mathrm{mg} / \mathrm{L} \mathrm{Cd}$ in drinking water for 28 consecutive days developed hypertension. Studies showed that one of the possible mechanism associated with hypertension development is disruption of the renin-angiotensin system which plays a major role in blood pressure regulation. ${ }^{24}$ The result of cadmium-induced hypertension is in agreement with a study done by Angeli et al. (2013) which demonstrated that acute exposure to Cd undoubtedly caused endothelial dysfunction by a mechanism relating to increased local release of angiotensin II, increased activity of COX-2, and NADPH oxidase. These mechanisms could contribute to the development of hypertension and atherosclerosis. ${ }^{25}$ In addition, the results of this study show the beneficial effects of omega- 3 in reducing the mean arterial pressure significantly in rats receiving $\mathrm{Cd}$ plus omeg-3 as compared with rats fed with $\mathrm{Cd}$ alone because omega- 3 improves arterial stiffness and endothelial function. ${ }^{26}$ In contrast, no significant differences in HR among all the groups were found. This finding is in line with a previous study done by Bini et al. (2015) on crayfish, which showed that exposure to $\mathrm{Cd}$ did not change crayfish heart rate frequency. ${ }^{27}$ Experimentally, exposure to cadmium causes impairment of baro-reflex control of heart rate by which the heart rate decreases when blood pressure increases. ${ }^{28}$ It has long been established that toxic agents like cadmium cause alteration of the lipid profile. ${ }^{29,30}$ Though, in the present study, no significant differences were found in the lipid profile between the control group and Cd-received rats only in TG, which was significantly increased. This can be related to the decreased activity of lipoprotein lipase enzyme, which is the key enzyme in TG hydrolysis. ${ }^{30}$ This finding is in agreement with results reported by other investigators that oral administration of $\mathrm{Cd}$ resulted in higher TG, and LDL-C levels in the serum of Cd-exposed rats compared with control. ${ }^{31}$ On the other hand, the administration of omega-3 along with cadmium exposing resulted in a significant increase in serum level of cholesterol, HDL, TG, and LDL. The same significant result could be seen in serum HDL when rats fed with $\mathrm{Cd}$ and omega-3 were compared to rats exposed only to cadmium. Studies have shown that omega-3 fatty acids have beneficial effects on plasma lipids. ${ }^{32}$ However, in the present study, the administration of omega-3 adversely affected the lipid profile since mixed results have been gotten. Determinations of normal sperm parameters are essential in the evaluation of male fertility. Following the contamination with $\mathrm{Cd}$, sperm count and sperm viability were reduced when they were compared to the control group, which were in agreement with results from a study done by Akinloye et al. (2006). ${ }^{33}$ This indicates that cadmium has a strong deleterious effect on spermatogenesis. The same results have been reported in the mice exposed to a high dose of cadmium which caused a decline in sperm count, and motility. ${ }^{34}$ Reduced number of sperms in Cd-received rats may be due to germ cell apoptosis and severe necrosis of the seminiferous tubule. ${ }^{35}$ On the other hand, supplementation with omega-3 has shown markedly improving in sperm parameters which can be due to the protective and antioxidant properties of omega- $3{ }^{36}$ Additionally, omega-3 fatty acids including docosahexaenoic and eicosapentaenoic acids are essential in maintaining the lipid bilayer properties of spermatozoa membrane which is in turn important for successful fertilization. Omega-3 supplement also plays a vital role in sperm maturation and sperm-oocyte cross talk. ${ }^{37}$ In addition, the results of the current study 
showed that the administration of cadmium plus omega-3 has significantly increased the serum level of FSH. This outcome is not following the expected results as dietary supplementation of omega- 3 decreases the serum levels of $\mathrm{FSH}^{38}$ A maximum reduction in gonadotropin levels has also been seen in rats exposed to cadmium since it is known that cadmium accumulate at the pituitary and induce apoptosis of anterior pituitary leading to decreases in secretion of $\mathrm{FSH}$ and $\mathrm{LH}^{39,40}$ However, significant reductions were observed in the serum levels of estradiol in both experimental groups as compared to the control group. Estradiol is a sex hormone that has a vital role in the reproduction functions and development of the gonadotropic. A study done by Chouchene et al. (2016) described Cd as a potent anti-estrogen in vivo and in vitro and provided evidence that $\mathrm{Cd}$ inhibits estrogen actions and have effects on estrogen signaling in the brain. ${ }^{41}$ The same inhibitory effect of $\mathrm{Cd}$ could be revealed by a study done on rats in which the $\mathrm{Cd}$ could mimic the effects of estrogen and estrogen-induced activity, and cell proliferation. ${ }^{42}$ Dietary supplementation of omega-3 could not improve the reduction of serum level of estradiol by cadmium. Changes in organ weights are often associated with treatment-related effects. ${ }^{43}$ Moreover, it has been observed that $\mathrm{Cd}$ administrated to experimental animals in this study caused a reduction in testis and caudal epididymis weights. In confirm, previous studies have also yielded similar results. ${ }^{34,44}$ It has also been demonstrated in earlier studies that antioxidant substances which are used for protection of tissue damage, prevent the weight loss of reproductive organs. In our study, the use of omega-3, together with $\mathrm{Cd}$ could not significantly prevent this adverse effect. Furthermore, the reduction of weight of sex glands is accompanied by a modification of the normal histological appearance. The results showed here are confirmed by noticeable alteration in the histological investigation of the testis, which showed a moderate to the severe arrest of spermatogenesis and Sertoli cells proliferation. In addition, severe congestion of intertubular blood vessels could be seen in rats treated with only cadmium compared with the control group. The results of our study confirm the results of the previous study performed by Aktas et al. (2011), which showed that a subcutaneous injection of $1 \mathrm{mg} / \mathrm{kg}$, Cd for one month, caused severe damage in the seminiferous tubules and testicular interstitium. ${ }^{45}$ The present study reports the protective effect of omega-3 against Cd-induced histological toxicity in the testis of rats receiving both $\mathrm{Cd}$ and omega-3, which show a mildly arrest in spermatogenesis and presence of spermatozoa in some of the tubular lumen.

\section{Conclusion}

Exposure of rats to cadmium dissolved in drinking water might have an increased risk of hypertension and impaired testicular function. Thus, the finding of the current study provides evidence that $\mathrm{Cd}$ could be an environmental risk factor for cardiovascular diseases and androgenic activity impairments. Supplementation with omega-3 can be considered potential therapeutic nutrients to protect against cardiovascular and reproductive toxicity induced by cadmium.

\section{Competing interests}

The author declares no competing interests.

\section{References}

1. Marettová E, Maretta M, Legáth J. Toxic effects of cadmium on testis of birds and mammals: a review. Anim Reprod Sci 2015; 155:1-10.

2. Sarkar AN, Ravindran GE, Krishnamurthy VI. A brief review on the effect of cadmium toxicity: from cellular to organ level. Int J Biotechnol Res 2013; 3(1):17-36.

3. Oliveira TF, Batista PR, Leal MA, Campagnaro BP, Nogueira BV, Vassallo DV, et al. Chronic Cadmium Exposure Accelerates the Development of Atherosclerosis and Induces Vascular Dysfunction in the Aorta of ApoE-/Mice. Biol Trace Elem Res 2018; 29:1-9. 
4. da Cunha Martins A, Carneiro MF, Grotto D, Adeyemi JA, Barbosa F. Arsenic, cadmium, and mercury-induced hypertension: mechanisms and epidemiological findings. J Toxicol Environ Health, Part B 2018; 21(2):61-82.

5. Asgary S, Movahedian A, Keshvari M, Taleghani M, Sahebkar A, Sarrafzadegan N. Serum levels of lead, mercury and cadmium in relation to coronary artery disease in the elderly: A crosssectional study. Chemosphere 2017; 180:540-4.

6. Djukić-Ćosić D, Jovanović MĆ, Bulat ZP, Ninković $M$, Maličević Ž, Matović $V$. Relation between lipid peroxidation and iron concentration in mouse liver after acute and subacute cadmium intoxication. J Trace Elem Med Biol 2008; 22(1):66-72.

7. Manna $P$, Sinha M, Sil PC. Cadmium induced testicular pathophysiology: prophylactic role of taurine. Reprod Toxicol 2008; 26(3-4):282-91.

8. Thompson J, Bannigan J. Cadmium: toxic effects on the reproductive system and the embryo. Reprod Toxicol 2008; 25(3):304-15.

9. Djuric A, Begic A, Gobeljic B, Stanojevic I, Ninkovic M, Vojvodic D, et al. Oxidative stress, bioelements and androgen status in testes of rats subacutely exposed to cadmium. Food Chem Toxicol 2015; 86:25-33.

10. Lamas CD, CuquettoLeite L, do Nascimento SE, Thomazini BF, Cordeiro GD, Predes FD, et al. Grape juice concentrate alleviates epididymis and sperm damage in cadmium intoxicated rats. Int $\mathrm{J}$ Clin Exp Pathol 2017; 98(2):86-99.

11. Wang L, Li Y, Fu J, Zhen L, Zhao N, Yang Q, et al. cadmium inhibits mouse sperm motility through inducing tyrosine phosphorylation in a specific subset of proteins. Reprod Toxicol 2016; 63:96-106.

12. Lacorte LM, Seiva FR, Rinaldi JC, Delella FK, Moroz A, Sarobo C, et al. caffeine reduces cadmium accumulation in the organism and enhances the levels of antioxidant protein expression in the epididymis. Reprod Toxicol 2013; 35:137-43.

13. Ismail TF, Aziz FM. The protective effect of omega-3 oil against the hepatotoxicity of cadmium chloride in adult and weanling rats. In AIP Conference Proceedings 2017 Sep 21 (Vol. 1888, No. 1, p. 020027). AIP Publishing.

14. O'Mahoney LL, Matu J, Price OJ, Birch KM, Ajjan RA, Farrar D, et al. Omega-3 polyunsaturated fatty acids favourably modulate cardiometabolic biomarkers in type 2 diabetes: a meta-analysis and meta-regression of randomized controlled trials. Cardiovasc Diabetol 2018; 17(1):98.

15. Ozen OA, Cosar M, Sahin O, Fidan H, Eser O, Mollaoglu $\mathrm{H}$, et al. The protective effect of fish $n-3$ fatty acids on cerebral ischemia in rat prefrontal cortex. J Neurol Sci 2008; 29(3):147.

16. Siegert E, Paul F, Rothe M, Weylandt KH. The effect of omega-3 fatty acids on central nervous system remyelination in fat-1 mice. BMC Neurosci 2017; 18(1):19.
17. Uygur R, Aktas C, Tulubas F, Uygur E, Kanter M, Erboga $M$, et al. Protective effects of fish omega 3 fatty acids on doxorubicin-induced testicular apoptosis and oxidative damage in rats. Andrologia 2014; 46(8):917-26.

18. Zhang J, Wang Y, Fu L, Feng YJ, Ji YL, Wang H, Xu DX. Subchronic cadmium exposure upregulates the mRNA level of genes associated to hepatic lipid metabolism in adult female CD1 mice. J Appl Toxicol 2018; 38(7):1026-35.

19. Nagahama $H$, Nakazaki $M$, Sasaki $M$, Kataoka-Sasaki Y, Namioka T, Namioka A, et al. Preservation of interhemispheric cortical connections through corpus callosum following intravenous infusion of mesenchymal stem cells in a rat model of cerebral infarction. Brain Res 2018; 1695:37-44.

20. Shabanian S, Farahbod F, Rafieian M, Ganji F, Adib A. The effects of Vitamin C on sperm quality parameters in laboratory rats following long-term exposure to cyclophosphamide. J Adv Pharm Technol Res 2017; 8(2):73.

21. Yucra S, Gasco M, Rubio J, Nieto J, Gonzales GF. Effect of different fractions from hydroalcoholic extract of Black Maca (Lepidiummeyenii) on testicular function in adult male rats. Fertil Steril 2008; 89(5):1461-7.

22. Ellenburg J, Drwiega J, Posey A, Goldberg M, Gordetsky J, Kolettis P. MP19-18 The use of formalin as a fixative for testicular biopsies. J Urol 2018; 199 (4):250-1.

23. Battan G, Tandon R, Vasenwala SM, Faruqi NA. Effect of methotrexate on testis. An experimental study on Albino rat. Annals of Interventional Medical and Dental Research. 2015; 1(3):170-4.

24. Broseghini-Filho GB, Almenara CC, Vescovi MV, Faria TD, Vassallo DV, Angeli JK, et al. Acute cadmium exposure reduces the local angiotensin I converting enzyme activity and increases the tissue metal content. Biol Trace Elem Res 2015; 166(2):149-56.

25. Angeli JK, Pereira CA, de Oliveira FT, Stefanon I, Padilha AS, Vassallo DV. Cadmium exposure induces vascular injury due to endothelial oxidative stress: the role of local angiotensin II and COX-2. Free Radic Biol Med 2013; 65:83848.

26. Qi X, Qin Z, Tang J, Han P, Xing Q, Wang K, et al. Omega-3 polyunsaturated fatty acids ameliorates testicular ischemia-reperfusion injury through the induction of Nrf2 and inhibition of NF-KB in rats. Exp Mol Pathol 2017;103(1):4450.

27. Bini G, Santini G, Chelazzi G. Pre-exposure to cadmium or zinc alters the heart rate response of the Crayfish procambarus clarkia towards copper. Bull Environ Contam Toxicol 2015; 95(1):12-7.

28. McGinnis WR, Audhya T, Edelson SM. Proposed toxic and hypoxic impairment of a brainstem locus in autism. Int $\mathrm{J}$ Environ Res Public Health 
29. Murugavel P, Pari L. Diallyltetrasulfide protects cadmium-induced alterations in lipids and plasma lipoproteins in rats. Nutr Res 2007; 27(6):356-61.

30. Larregle EV, Varas SM, Oliveros LB, Martinez LD, Antón R, Marchevsky E, et al. Lipid metabolism in liver of rat exposed to cadmium. Food Chem Toxicol 2008; 46(5):1786-92.

31. Samarghandian S, Azimi-Nezhad M, Shabestari MM, Azad FJ, Farkhondeh T, Bafandeh F. Effect of chronic exposure to cadmium on serum lipid, lipoprotein and oxidative stress indices in male rats. Interdiscip Toxicol 2015; 8(3):151-4.

32. Nourbakhsh M, Nourbakhsh M, Azar MR. The effect of n-3 PUFA on lipid profile, inflammation and insulin resistance. Endocrine Abstracts 2018; 56:536.

33. Akinloye O, Arowojolu AO, Shittu OB, Anetor JI. Cadmium toxicity: a possible cause of male infertility in Nigeria. Reprod Biol 2006; 6(1):1730.

34. Monsefi M, Alaee S, Moradshahi A, Rohani L. Cadmium-induced infertility in male mice. Environ Toxicol Chem 2010; 25(1):94-102.

35. Asadi MH, Zafari F, Sarveazad A, Abbasi M, Safa M, Koruji $M$, et al. Saffron improves epididymal sperm parameters in rats exposed to cadmium. Nephrourol Mon 2014; 6(1):e12125.

36. Hosseini B, Nourmohamadi M, Hajipour S, Taghizadeh M, Asemi Z, Keshavarz SA, et al. The effect of omega-3 fatty acids, EPA, and/or DHA on male infertility: A systematic review and meta-analysis. J Diet Suppl 2018; 16:1-2.

37. Tang LX, Yuan DJ, Wang QL, Jiang F, Guo J, Tang YG, et al. Association of decreased spermatozoa omega-3 fatty acid levels and increased oxidative DNA damage with varicocele in infertile men: a case control study. Reprod Fertil Dev 2016; 28(5):648-54.

38. Bauer JL, Kuhn K, Al-Safi Z, Harris MA, Eckel $\mathrm{RH}$, Bradford AP, et al. Omega-3 fatty acid supplementation significantly lowers FSH in young normal weight women. Fertil Steril 2017; 108(3):257-8.

39. Pillai A, Priya L, Gupta S. Effects of combined exposure to lead and cadmium on the hypothalamic-pituitary axis function in proestrous rats. Food Chem Toxicol 2003; 41(3):379-84.

40. Yang XF, Zhu W, Wei Q, Lin ZN. Effect on apoptosis of anterior pituitary induced by cadmium chloride and its relations with p38 MAPK \& ERK1/2 passway. Wei sheng yanjiu. Am J Hyg 2005; 34(6):681-4.

41. Chouchene L, Pellegrini E, Gueguen MM, Hinfray $N$, Brion $F$, Piccini B, et al. Inhibitory effect of cadmium on estrogen signaling in zebrafish brain and protection by zinc. J Appl Toxicol 2016; 36(6):863-71.

42. Johnson MD, Kenney N, Stoica A, Hilakivi-Clarke L, Singh B, Chepko G, et al. cadmium mimics the in vivo effects of estrogen in the uterus and mammary gland. Nat Med 2003; 9(8):1081.
43. Sellers RS, Mortan D, Michael B, Roome N, Johnson JK, Yano BL, et al. Society of Toxicologic Pathology position paper: organ weight recommendations for toxicology studies. Toxicol Pathol 2007; 35(5):751-5.

44. Arafa $\mathrm{MH}$, Mohammad NS, Atteia $\mathrm{HH}$. Fenugreek seed powder mitigates cadmiuminduced testicular damage and hepatotoxicity in male rats. Exp Toxicol Pathol 2014; 66(7):293300.

45. Aktas C, Kanter M, Erboga M, Ozturk S. Anti-apoptotic effects of curcumin on cadmiuminduced apoptosis in rat testes. Toxicol Ind Health 2012; 28(2):122-30. 